\title{
Sternoclavicular Joint Infection: Classification of Resection Defects and Reconstructive Algorithm
}

\author{
Janna Joethy ${ }^{1}$, Chong Hee Lim², Heng Nung Koong ${ }^{3}$, Bien-Keem Tan ${ }^{1}$ \\ ${ }^{1}$ Department of Plastic, Reconstructive and Aesthetic Surgery, Singapore General Hospital; ${ }^{2}$ National Heart Centre; ${ }^{3}$ National Cancer Centre, \\ Singapore
}

Background Aggressive treatment of sternoclavicular joint (SCJ) infection involves systemic antibiotics, surgical drainage and resection if indicated. The purpose of this paper is to describe a classification of post resectional SCJ defects and highlight our reconstructive algorithm. Defects were classified into $A$, where closure was possible often with the aid of topical negative pressure dressing; $B$, where parts of the manubrium, calvicular head, and first rib were

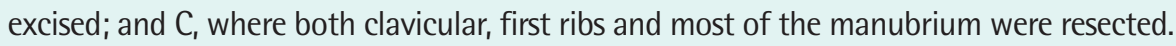

Methods Twelve patients (age range, 42 to 72 years) over the last 8 years underwent reconstruction after $\mathrm{SCJ}$ infection. There was 1 case of a type A defect, 10 type B defects, and 1 type $C$ defect. Reconstruction was performed using the pectoralis major flap in 6 cases (50\%), the latissimus dorsi flap in 4 cases (33\%), secondary closure in 1 case and; the latissimus and the rectus flap in 1 case.

Results All wounds healed uneventfully with no flap failure. Nine patients had good shoulder motion. Three patients with extensive clavicular resection had restricted shoulder abduction and were unable to abduct their arm past $90^{\circ}$. Internal and external rotation were not affected. Conclusions We highlight our reconstructive algorithm which is summarised as follows: for an isolated type B SCJ defect we recommend the ipsilateral pectoralis major muscle for closure. For a type $\mathrm{C}$ bilateral defect, we suggest the latissimum dorsi flap. In cases of extensive infection where the thoracoacromial and internal mammary vessels are thrombosed, the pectoralis major and rectus abdominus cannot be used; and the latissimus dorsi flap is chosen.

Keywords Sternoclavicular joint / Infectious arthritis / Surgical flap
Correspondence: Bien-Keem Tan Department of Plastic, Reconstructive and Aesthetic Surgery, Singapore General Hospital, Outram Road, Singapore 169608

Tel: +6563214686

Fax: +6562209340

E-mail: bienkeem@gmail.com

Received: 5 Jun 2012 • Revised: 10 Jul 2012 • Accepted: 17 Jul 2012

pISSN: 2234-6163 • elSSN: 2234-6171 • http://dx.doi.org/10.5999/aps.2012.39.6.643 • Arch Plast Surg 2012;39:643-648

\section{INTRODUCTION}

Septic arthritis of the sternoclavicular joint (SCJ) is a rare clinical entity that represents $1 \%$ of all bone and joint infections $[1,2]$. Common predisposing factors include diabetes, rheumatoid arthritis, intravenous drug use, intraarticular injection, and immunosuppressive disorders [3]. It is often missed in patients with multiple comorbidities.
In early stages, the infection is sealed off by the joint capsule resulting in diagnostic delays. The inability of the capsule to distend leads to an initial build up of pressure within the joint which is subsequently released through fistulation, leading to cutaneous abscesses or mediastinitis [2,4]. Early diagnosis of SCJ infection requires a high index of suspicion and a confirmatory computed tomography $(\mathrm{CT})$ scan.

Treatment is variable and ranges from simple drainage to ex-

Copyright $\odot 2012$ The Korean Society of Plastic and Reconstructive Surgeons

This is an Open Access article distributed under the terms of the Creative Commons Attribution Non-Commercial License (http://creativecommons.org/

licenses/by-nc/3.0/) which permits unrestricted non-commercial use, distribution, and reproduction in any medium, provided the original work is properly cited.

www.e-aps.org 
tensive debridement as has been described in our earlier series $[5,6]$. We highlight our reconstructive approach to the management of cases where the debridement is substantial and the wound cannot be easily closed. In such cases, the defect size and exposure of critical structures dictate our reconstruction. To date, there is little in the literature detailing surgical reconstruction of SCJ infections. The purpose of this paper is to classify SCJ defects and describe our reconstructive algorithm.

\section{METHODS}

Twelve patients ( 7 female, 5 male) over the last 8 years underwent reconstruction after SCJ infection. The age ranged from 42 to 72 years old (mean, 59 years). A single case of bilateral SCJ infection is included and we discuss the reconstruction of this rare entity. After joint resection, negative pressure therapy was commenced to ensure optimization of patient and wound prior to reconstruction. The patients were optimized in terms of nutrition, sepsis and co-morbidities. Once both wound and patient were ready, reconstruction was performed according to our algorithm (Fig. 1).

\section{RESULTS}

Diabetes $(n=7)$ followed by hypertension $(n=4)$ were the commonest co-morbidities but often our patients had other medical conditions (Table 1). The commonest pathogen identi- fied was Staphylococcus aureus (S. aureus, $\mathrm{n}=6$ ) of which 2 were methicillin resistant. Escherichia coli $(E$. coli, $\mathrm{n}=3)$, Streptococcus pyogenes (S. pyogenes, $\mathrm{n}=2$ ) and Pseudomonas aeruginosa ( $P$. aeruginosa, $\mathrm{n}=1$ ) were the others.

In these unwell patients, we started broad spectrum antibiotics

Fig. 1. Reconstructive algorithm taking into account the size of the defect, the vessels available and our preference for flap coverage.

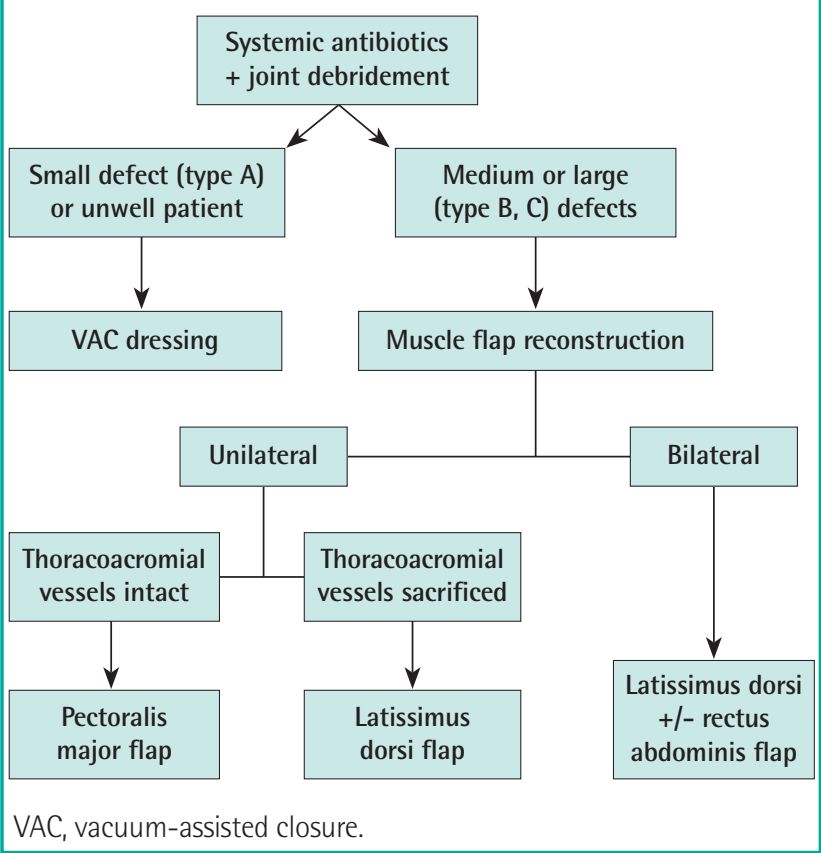

Table 1. Showing our patients, their co-morbidities, type of defect, the reconstruction and the functional outcome

\begin{tabular}{|c|c|c|c|c|c|c|c|}
\hline $\begin{array}{l}\text { Patient } \\
\text { No. }\end{array}$ & $\begin{array}{l}\text { Age }(y r) / \\
\text { Sex }\end{array}$ & Risk factors & Cause & $\begin{array}{l}\text { Type of } \\
\text { defect }^{\text {a) }}\end{array}$ & Reconstruction & Outcome & $\begin{array}{l}\text { Average } \\
\text { follow-up } \\
\quad \text { (mo) }\end{array}$ \\
\hline 1 & $57 / F$ & $\begin{array}{l}\text { Systemic lupus erythematosus, } \\
\text { interstitial lung disease, asthma }\end{array}$ & Central line insertion & A & Secondary closure & Uneventful recovery & 24 \\
\hline 2 & $65 / F$ & $\begin{array}{l}\text { Rheumatoid arthritis and a previous } \\
\text { cerebrovascular accident }\end{array}$ & Sepsis & B & Latissimus dorsi flap & Uneventful recovery & 36 \\
\hline 3 & $45 / \mathrm{M}$ & Non insulin dependent diabetes mellitus & Sepsis & $\mathrm{B}$ & Pectoralis major flap & Uneventful recovery & 36 \\
\hline 4 & $46 / \mathrm{M}$ & Hypertension and hypercholesterolemia & Sepsis & $\mathrm{B}$ & Contralateral pectoralis major flap & Uneventful recovery & 18 \\
\hline 5 & $53 / F$ & $\begin{array}{l}\text { Non insulin dependent diabetes mellitus, } \\
\text { hypothyroidism and hypertension }\end{array}$ & Unknown & C & $\begin{array}{l}\text { Latissimus dorsi and rectus } \\
\text { abdominus muscle flap }\end{array}$ & Uneventful recovery & 36 \\
\hline 6 & $62 / F$ & Ischaemic heart disease & Central line insertion & B & Pectoralis major flap & Frozen shoulder & 48 \\
\hline 7 & $58 / \mathrm{M}$ & Hypertension, asthma & Central line insertion & $\mathrm{B}$ & Pectoralis major flap & Uneventful recovery & 24 \\
\hline 8 & $68 / \mathrm{M}$ & Insulin dependent diabetes mellitus & Sepsis & B & Latissimus dorsi muscle flap & Uneventful recovery & 60 \\
\hline 9 & $74 / \mathrm{M}$ & $\begin{array}{l}\text { Renal failure, non insulin dependent diabetes } \\
\text { mellitus }\end{array}$ & Sepsis & $\mathrm{B}$ & Pectoralis major flap & $\begin{array}{l}\text { Decreased shoulder } \\
\text { abduction }\end{array}$ & 48 \\
\hline 10 & $74 / F$ & Insulin dependent diabetes mellitus & Sepsis & B & Pectoralis major flap & $\begin{array}{l}\text { Decreased shoulder } \\
\text { abduction }\end{array}$ & 36 \\
\hline 11 & $63 / F$ & Renal failure & Central line insertion & $\mathrm{B}$ & Latissimus dorsi flap & Uneventful recovery & 18 \\
\hline 12 & $42 / F$ & $\begin{array}{l}\text { Non insulin dependent diabetes mellitus, } \\
\text { hypothyroidism, hypertension }\end{array}$ & Sepsis & B & Latissimus dorsi flap & Uneventful recovery & 18 \\
\hline \multicolumn{8}{|c|}{$\begin{array}{l}\text { a) Type of defect refers to our classification of sternoclavicular defects (Fig. 5). In type A defects, the defect is small and closure is possible with the aid of topical negative pressure } \\
\text { dressing. In type B defects, part of the manubrium, clavicular head and first rib are excised. In type C defects, the defect is bilateral involving both clavicular and first rib and mos } \\
\text { of the manubrium. }\end{array}$} \\
\hline
\end{tabular}


until sensitivities were available. High dose cloxacillin (S. aure$u s$ ), vancomycin (methicillin resistant $S$. aureus) or penicillin (S. pyogenes) were used. Gram negative bacteria were treated with imipenem or tazocin (P. aeruginosa, E. coli). All antibiotic usage was used in consultation with infectious disease physicians.

Reconstruction was performed by using the pectoralis major flap in 6 cases (50\%), the latissimus dorsi flap in 4 cases (33\%), secondary closure in 1 case and another required two flaps: the latissimus dorsi and the rectus flap. All wounds healed uneventfully and there was no flap failure.

Three patients had restricted shoulder abduction and were unable to abduct their arm past 90 degrees. These patients had extensive clavicular resection. Internal and external rotation were not affected.

We highlight a few illustrative cases as follows.

\section{Case 1}

Type B defect (Fig. 2): latissimus dorsi musculocutaneous flap reconstruction. A 65-year-old female with rheumatoid arthritis and a previous cerebrovascular accident presented with sepsis. She underwent a CT chest which showed a collection at her left SCJ with air pockets and mediastinal involvement. The collection was drained and washed out. Part of the manubrium, two-thirds of the clavicle and first rib were excised. As part of debridement, the left internal mammary artery and thoracoacromial artery were ligated. A latissimus dorsi flap was used to reconstruct this defect.

\section{Case 2}

Type B defect (Fig. 3): contralateral pectoralis major musculocutaneous flap reconstruction. A 46-year-old man with hypertension and hypercholesterolemia presented with multiple lymph nodes at the cervical chain and left axilla. A CT neck revealed a left SCJ infection with multiple abcessess involving the sternocleidomastoid muscles and the left pectoralis major muscle. He underwent excisional debridement and coverage using the contralateral pectoralis major.

\section{Case 3}

Type $\mathrm{C}$ defect (Fig. 4): latissimus dorsi and rectus abdominus muscle flap reconstruction. A 53-year-old lady with diabetes, hypothyroidism and hypertension presented with diffuse swelling

\section{Fig. 2. Type B defect}

Latissimus Dorsi reconstruction. Part of the manubrium, two-thirds of the clavicle and first rib were excised in this 65-year-old lady with sepsis. As part of excisional debridement, the left internal mammary artery and thoracoacromial artery were ligated. A latissimus dorsi flap was used to reconstruct this defect. (A) Computed tomography scan showing the collection. (B) Insetting the the latissimus dorsi (LD) flap. (C) Two months postoperative photo.
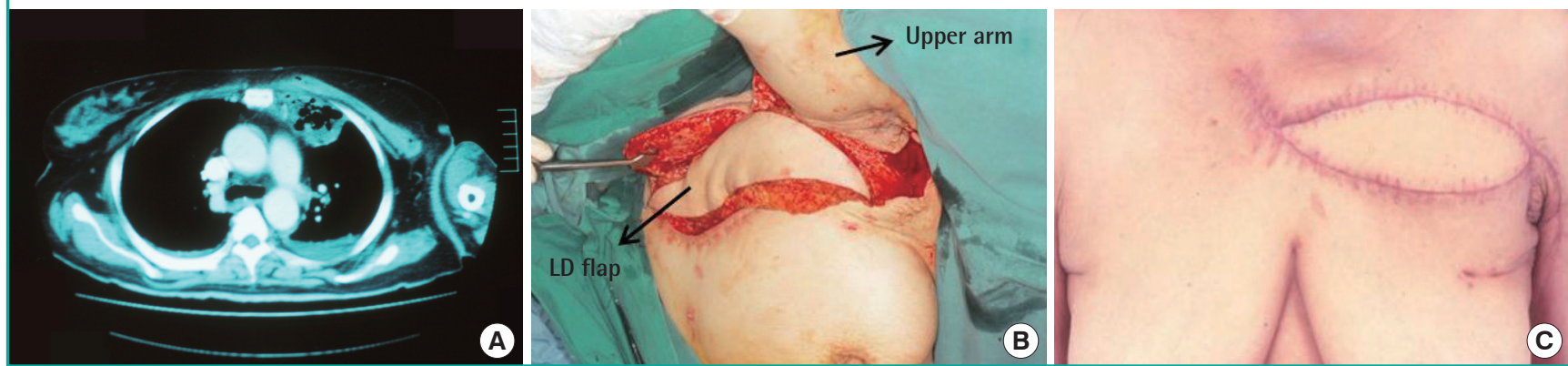

Fig. 3. Type B defect

Contralateral pectoralis major reconstruction showing a 46-year-old man with (A) pus eroding into ipsilateral pectoralis major. (B) Mobilization of contralateral pectoralis myocutaneous major flap. (C) One year postoperatively.
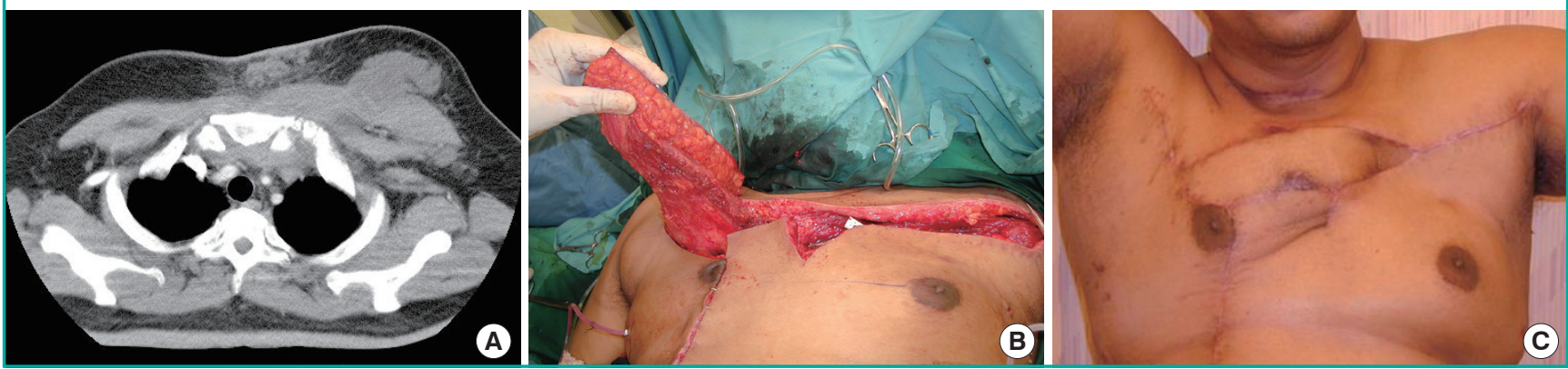


\section{Fig. 4. Type $\mathrm{C}$ defect}

Latissimus dorsi and rectus abdominus reconstruction. A 53-year-old lady with bilateral sternoclavicular joint (SCJ) infection. (A) Showing the wound following debridement with excision of the entire manubrium and upper half of the sternum. (B) After tunnelling the latissimus dorsi (LD) muscle on the left and rectus abdominus (RA) muscle on the right. (C) One year postoperative view.
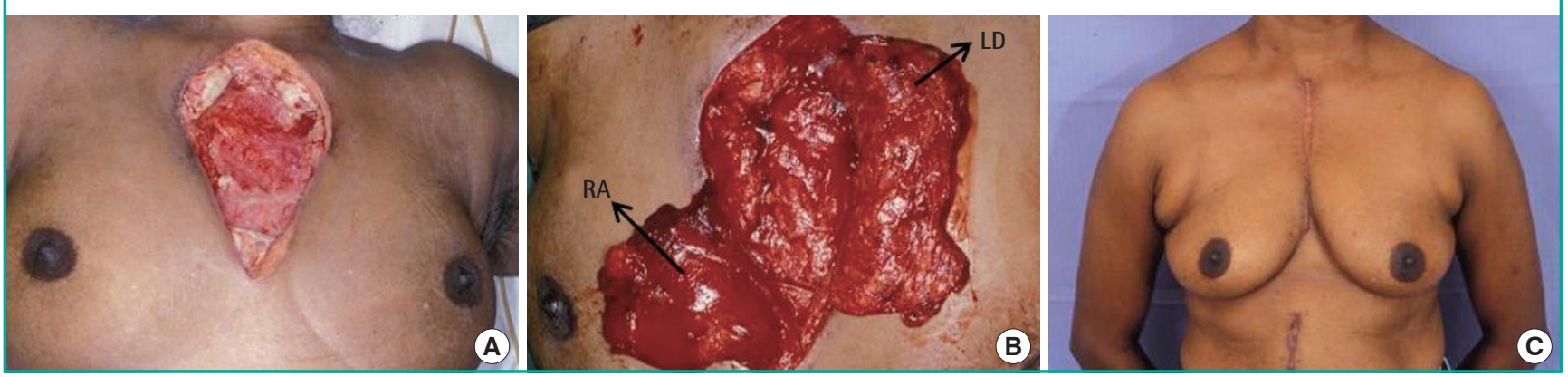

over her chest. A CT confirmed bilateral SCJ infection. She underwent wound debridement with resection of her manubrium and upper sternum, bilateral clavicular heads and, both first ribs. The large residual defect was closed with a latissimus dorsi and rectus abdominus muscle flap.

\section{DISCUSSION}

Existing literature categorizes SCJ infection but not SCJ resection $[8,9]$. We have classified the post resectional SCJ defect and based our treatment accordingly. From our series, three types of defects exist (Fig. 5).

\section{Type A}

In early, well contained infections, the joint is stable and CT scanning shows infection confined to the joint with joint destruction and thickening of periarticular tissues. Following drainage and limited SCJ debridement (Figs. 5A, 6), the defects are small and lend themselves to secondary closure often with the aid of negative pressure dressing $[2,7]$. In such cases, we preserved the overlying pectoralis major for later coverage.

\section{Type B}

In extensive unilateral infection (Figs. 2, 7), there is spread beyond the joint to involve adjacent bone and rib as can be seen on CT with bony and joint destruction along with air pockets in subcutaneous layer or deeper in the anterior mediastinum. These cases will require at least excision of part of the clavicular head, part of the first rib, and part of the manubrium (Fig. 5B), leading to exposure of the thymus, brachiocephalic veins, and in some cases, the pleura. In these instances, we aim to cover the exposed bone ends along with any exposed underlying vital structures. We also introduce fresh blood supply in the form of a muscle flap to control infection. The preferred reconstructive

\section{Fig. 5. Classification of sternoclavicular defects}

In type A defects, closure is possible with the aid of topical negative pressure dressing. In type B defects, part of the manubrial head, clavicular head and first rib are excised. These defects are typically closed with an ipsilateral pectoralis major flap or an ipsilateral latissimus dorsi flap. In type C defects, the defect is bilateral involving both clavicular heads and first ribs and most of the manubrium. Closure here is performed with a latissimus dorsi flap and depending on the inferior extent of the wound, a rectus abdominis flap is used.
A

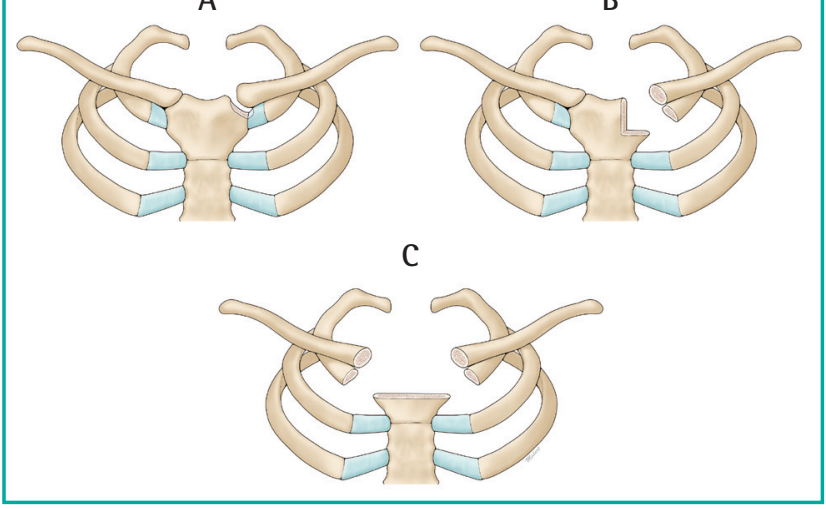

option was the ipsilateral pectoralis major flap based on the thoraco-acromial vessels. The pectoralis major was disinserted from the humerus and shifted medially to fill the defect. Externally the muscle was skin grafted if the wound was tight. In Fig. 3 , where the infective process involved the ipsilateral pectoralis major, we used the contralateral pectoralis major with a long vertical skin paddle. The muscle alone could not reach the defect; it was the extended skin paddle that covered the wound. In cases where the thoraco-acromial vessels are of dubious viability, or when the vessels have been sacrificed during resection, we opted for latissimus dorsi flap reconstruction (Fig. 2).

\section{Type C}

More extensive infection resulted in resection of both clavicular 


\section{Fig. 6. Type A defect}

No reconstruction. (A) A 57-year-old lady with systemic lupus erythematosus, interstitial lung disease and asthma had an internal jugular line inserted for postoperative monitoring. Three days post insertion, there was a tender swelling overlying her clavicle. (B) The strong anterior and posterior sternoclavicular ligaments wall off the infection and often result in a high pressure collection.
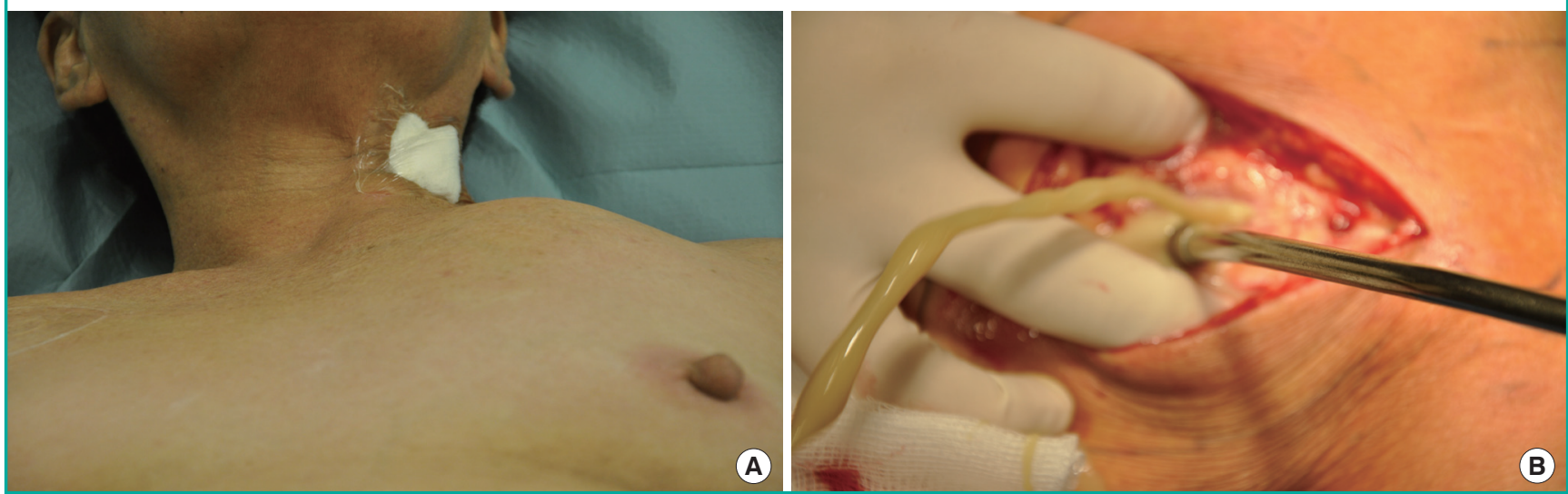

\section{Fig. 7. Type B defect}

Pectoralis major reconstruction. Showing a 45-year-old man with diabetes who presented with diabetic ketoacidosis secondary to sepsis. A computed tomography scan revealed a collection at the sternoclavicular joint. (A) Mobilisation of the pectoralis major to cover the defect. (B) Two months postoperative photo.

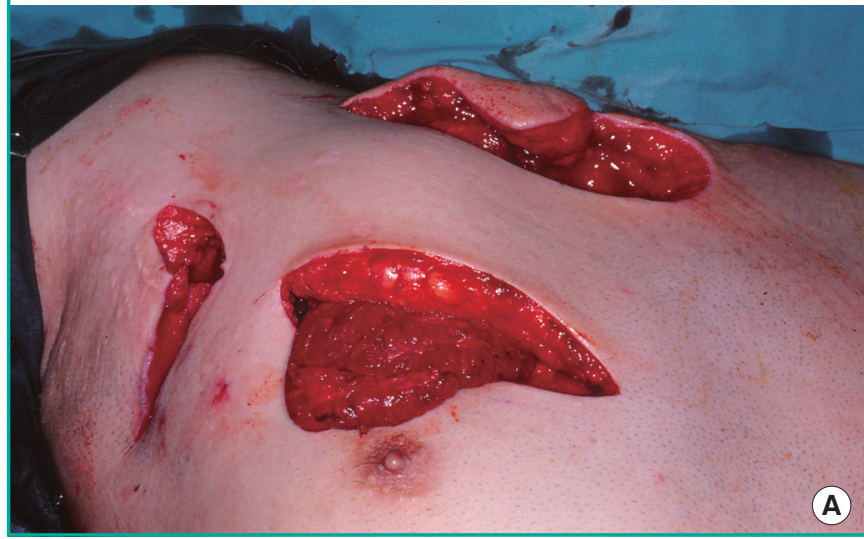

heads and both first ribs and the entire manubrium (Fig. 5C). The anterior chest became flail and there was loss of insertion of accessory muscles of ventilation. The priority here was to preserve the pectoralis major muscles to prevent destabilizing the chest and shoulders further. In Fig. 4, due to the large expanse of dead space, we used a latissmus dorsi and a rectus muscle. If the defect was confined to the manubrium, the latissmus dorsi flap alone would have been sufficient.

After SCJ resection, we constantly battle with instability of the shoulder girdle and movement of the thorax. This is in contrast with other regions like the lower extremity where immobilization is easily accomplished leading to earlier wound healing. There is little in the current literature for rigid fixation and joint replacement of the SCJ. The shoulder girdle articulates with the SCJ and with the removal of the medial clavicle, the clavicular

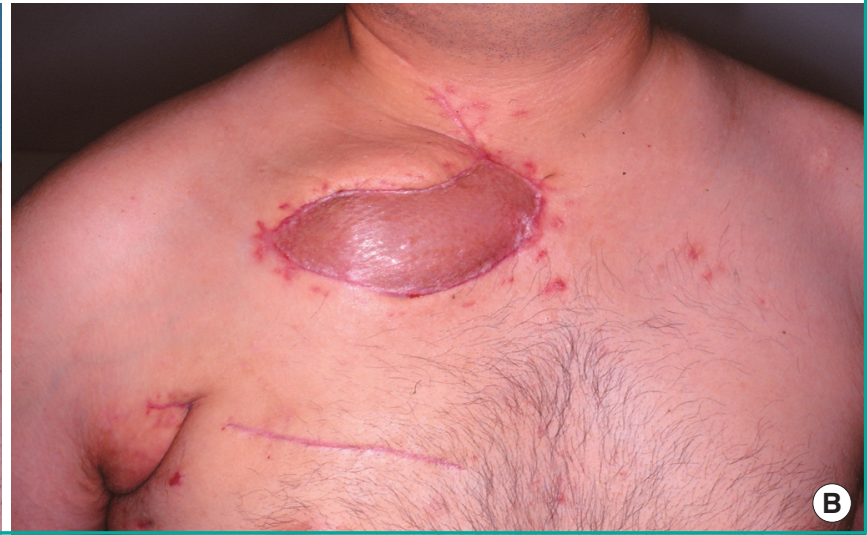

strut is lost affecting shoulder abduction. We noticed this in 3 patients, all of whom had long segment clavicluar resection. One patient developed a frozen shoulder. Thus, we recommend aggressive physiotherapy 3 weeks after surgery.

Despite our elaborate reconstructive algorithm, the patients' comorbidities were taken into account. Most were critically ill with diabetes or chronic renal failure. In such cases, it was important to hold off surgery prior to optimization. Topical negative pressure dressing was used to bide time allowing improvement of nutrition, clearance of sepsis and control of comorbid conditions.

\section{REFERENCES}

1. Bar-Natan M, Salai M, Sidi Y, et al. Sternoclavicular infec- 
tious arthritis in previously healthy adults. Semin Arthritis Rheum 2002;32:189-95.

2. Ross JJ, Shamsuddin H. Sternoclavicular septic arthritis: review of 180 cases. Medicine (Baltimore) 2004;83:139-48.

3. El Ibrahimi A, Daoudi A, Boujraf S, et al. Sternoclavicular septic arthritis in a previously healthy patient: a case report and review of the literature. Int J Infect Dis 2009;13:e11921.

4. Burkhart HM, Deschamps C, Allen MS, et al. Surgical management of sternoclavicular joint infections. J Thorac Cardiovasc Surg 2003;125:945-9.

5. Lim CH, Lim J, Naik MJ, et al. Surgical management of sternoclavicular joint infection. Asian Cardiovasc and Thorac
Ann 2001;9:291-5.

6. Song HK, Guy TS, Kaiser LR, et al. Current presentation and optimal surgical management of sternoclavicular joint infections. Ann Thorac Surg 2002;73:427-31.

7. Puri V, Meyers BF, Kreisel D, et al. Sternoclavicular joint infection: a comparison of two surgical approaches. Ann Thorac Surg 2011;91:257-61.

8. Abu Arab W, Khadragui I, Echave V, et al. Surgical management of sternoclavicular joint infection. Eur J Cardiothorac Surg 2011;40:630-4.

9. Nusselt T, Klinger HM, Freche S, et al. Surgical management of sternoclavicular septic arthritis. Arch Orthop Trauma Surg 2011;131:319-23. 